\title{
Bibliometric analysis of machining of titanium alloy research
}

\author{
Gaurav Gaurav $^{\mathrm{a}}$, Abhay Sharma ${ }^{\mathrm{b}}$, G.S. Dangayach ${ }^{\mathrm{a}, *}$, M.L. Meena ${ }^{\mathrm{a}}$ \\ ${ }^{a}$ Department of Mechanical Engineering, Malaviya National Institute of Technology Jaipur, Jaipur, 302017, India \\ ${ }^{\mathrm{b}}$ KU Leuven, Faculty of Engineering Technology, Department of Materials Engineering, Campus De Nayer, Sint-Katelijne Waver, 2860, Belgium
}

\section{A R T I C L E I N F O}

\section{Article history:}

Received 1 October 2020

Received in revised form 9 October 2020

Accepted 12 October 2020

Available online $\mathrm{xxxx}$

\section{Keywords:}

Bibliometric Analysis

Co-citation Analysis

Machining

Titanium Alloy

Web of Science (WoS)

\begin{abstract}
A B S T R A C T
This paper aims to acquaint the readers about the research trends in machining of titanium alloy related literature based on the data collected from Web of Science (WoS) databases using bibliometric analysis. A total of 1291 results were obtained from WoS database. The results were analyzed based on aspects like distribution of the obtained research documents based on language, type, subject areas covered, total publications of authors, and citation counts of authors over the years in WoS database. Most of the publications are either in the engineering and material science domain. Further, lists of most productive authors, institutions, countries (along with geographical representation) are presented. China is the leading country in this research field but the Nanjing University of Aeronautics and Astronautics of China have the highest number of publications among all other institutes around the world. The author's keywords co-occurrence analysis network is visualized using VOS viewer. The study shows that 'Minimum quantity lubrication (MQL)', 'nanofluid', 'cryogenic machining', 'cutting temperature', 'CFD', 'microstructure', 'sustainable machining, 'green machining', 'tool wear', 'micromachining', 'optimization parameters', 'tool life' with major machining process like turning, milling, grinding, drilling, EDM and WEDM, etc. are the most recent keywords that indicate the hot topics and future research directions in the machining of titanium alloy field. This study also shows that the annual growth rate in machining of titanium alloy research is $16.94 \%$, which indicates that machining of titanium alloy research has gained rapid attention since 2016 and gradually evolved over the years. By referring to this paper, researchers will be able to make calculated decisions and will get useful information for future research directions.

(c) 2020 Elsevier Ltd. All rights reserved.

Selection and peer-review under responsibility of the scientific committee of the International Conference on Advances in Materials Processing \& Manufacturing Applications.
\end{abstract}

\section{Introduction}

In many industrial applications, the continuous development of new materials and the continuous requirements for engineers to manufacture complex parts within tighter tolerances are growing substantially [1]. From this perspective, Machining of rare materials, such as titanium alloy is show high significance. Titanium alloys are widely used in medical instruments, aerospace industry, and defence applications due to their excellent properties such as high strength to weight ratio, high-temperature resistance, and resistance to corrosion and biocompatibility [2]. However, the Machining of titanium alloys has gained attention due to their low thermal conductivity, extensive application of these alloys and high chemical reactivity with cutting tool materials results in poor machinability. Therefore, various techniques such as dry machining, flood Lubrication, cryogenic cooling, and MQL has been

\footnotetext{
* Corresponding author.

E-mail address: dangayach@gmail.com (G.S. Dangayach).
}

used for machining of these alloys [3]. During Machining of Titanium alloy, most of the heat generated is conducted to the cutting tool because these alloys have low thermal conductivity results in poor surface quality and high tool wear [4]. Therefore, it is necessary to use suitable cutting fluid to prevent rapid tool wear [5]. In recent decades, many researchers have been working to improve the machinability of titanium alloy (Ti-6Al-4 V) by testing different lubrication strategies such as flood lubrication [6], cryogenic cooling [7], multi-point injection MQL [8]. To address the key difficulties in the machining of titanium alloys, study over the last few decades has paid careful attention to the production of new cutting tool materials and the enhancement of existing tool designs [4,5,915]. Moreover, comprehensive machinability studies have also been carried out to investigate the correct combination of cutting instruments, machine tools, and cutting parameters. Also, many researchers have developed and implemented new technology and method such as minimum quantity lubrication (MQL), cryogenic cooling, different cooling, and lubrication systems, minimum quantity cooling lubrication (MQCL), multi-point injection 
MQL, nanofluid lubrication, sustainable cooling method, sustainable lubrication fluid, and laser-assisted machining, etc to address the key difficulties in the machining of titanium alloys [13-29]. Most of the previous review studies use qualitative methods to analyze the existing literature, so they failed to describe the overall paradigm of the research field. To the best of our knowledge, few studies have combined quantitative methods with visualization methods to explore the machining of titanium alloy research. This is essential to demonstrate the progress of the machining of titanium alloy literature. Therefore, there is an urgent need to critically review the research in the field of machining of titanium alloy and to suggest a way forward. To fill this gap, Two-level analysis including bibliometric and visualization analysis has been used. In this paper, a detailed bibliometric analysis of the research field of machining of titanium alloy was discussed. The main objective of this article is to explore the ideas and opportunities of the selected literature through bibliometric and visualization analysis for the period from 1st January 2000 to 31th December 2019. The selected articles have been analysis related to trend analysis, author analysis, discipline wise analysis, source analysis, countrywise analysis, institution wise analysis, and keyword analysis.

\section{Research data collection and methodology}

This study uses a mixed approach that integrates bibliometric and visualization analysis. Bibliometric is a statistical analysis of books, articles, or other publications. This term was first coined by Prichard in 1969 [30]. Bibliometric analysis is a systematic method that can quantitatively discover the trend of publication and investigate the critical points of emerging issues, and assess academic research quality from diverse viewpoints [31]. For bibliometric analysis, data were extracted in CSV and plain text file format from the Web of Science (WoS) database from the year 1st January 2000 to 31th December 2019. The WoS produced by the Institute for Scientific Information (ISI) and maintained by Clarivate Analytics and also known for the comprehensive and quality sources of data for bibliometric analysis in the area of science and technology. To carry out this research web of science core collection database was selected. The search strategy used to retrieve the data on machining of titanium alloy is tabulated in table 1 . The search string was so selected that it could cover every title containing fully or partly the terms connected to machining of titanium alloy. The search field was set to article title only at the time of searching from WoS database.

Microsoft Excel, Bibliometrix [33], and VoS viewer [32] were used to analyze the results imported from WoS databases because of its high degree of visualizing bibliometric networks and flexibility in adjusting the input data. The results using search strings were analyzed based on aspects like distribution of the obtained research documents based on language, type, subject areas covered, total publications of authors, and citation counts of authors over the years. Further, lists of most productive authors, institutions, countries (along with geographical representation) are presented. The main Information about the extracted data is

Table 1

Search Criteria.

\begin{tabular}{|c|c|}
\hline $\begin{array}{l}\text { Database and Date } \\
\text { of search }\end{array}$ & WoS and $27 / 09 / 2020$ \\
\hline Search String & $\begin{array}{l}\text { ("Titanium alloy" OR “Titanium” OR “Ti-6Al-4 V” OR } \\
\text { "Ti6Al4V") AND ("Turning” OR “Milling” OR “Grinding” } \\
\text { OR “Drilling” OR “Tapping” OR “Boring" OR “Reaming" } \\
\text { OR “Machining") }\end{array}$ \\
\hline Search in fields & Article Title \\
\hline Document Type & All \\
\hline
\end{tabular}

tabulated in table 2 . The extracted information is divided into five parts i.e. key details regarding data, document types, document contents, authors, and author's collaboration. A total of 1291 records were found from WoS database based on the matched the above-mentioned search criteria. It is observed that articles 1174 (90.9\%) have the main contribution in document types in WoS database due to its broader coverage of technical and scientific literature.

\section{Result and discussion}

\subsection{Annual production and citation trend analysis}

The literature on machining of titanium alloy has been receiving rapid attention since 2016 and gradually evolved over the years. The annual growth rate in machining of titanium alloy research is $16.94 \%$. Publications trend from 1st January 2000 to 31th December 2019 based on the annual production and citations count is shown in Fig. 1. As can be seen from Fig. 1, the number of publications has increased significantly since 2000 . From the year 2000 to 2014 research growth related to machining of titanium alloy was slow. The growth in this research field was increased rapidly since 2016 till it reaches its highest peak in the year 2019 with 215 articles. From this trend, it is visible that the number of machining of titanium alloy related publications will grow in the forthcoming years.

Table 3 shows the total annual production and citation count. From Fig. 1, it is seen that there is a serious downfall in the citation count from the year 2000 to 2019. However, mean total citations (TC) per year is not much affected and almost constant around 4. Where ' $\mathrm{N}$ ' stands for no of publications.

\subsection{Top productive authors impact analysis}

Recognizing authors with the highest production and impact is a significant consideration for obtaining an overview of machining

Table 2

Main information extracted from WoS database.

\begin{tabular}{|c|c|}
\hline \multicolumn{2}{|l|}{ Main Information About Data } \\
\hline Timespan & 2000:2019 \\
\hline Sources (Journals, Books, etc) & 255 \\
\hline Documents & 1291 \\
\hline Average years from publication & 5.82 \\
\hline Average citations per documents & 22.37 \\
\hline Average citations per year per doc & 3.074 \\
\hline References & 19,765 \\
\hline \multicolumn{2}{|l|}{ Document Types } \\
\hline Article & $1174(90.9 \%)$ \\
\hline Article; Proceedings Paper & $81(6.3 \%)$ \\
\hline Correction & $2(0.2 \%)$ \\
\hline Editorial Material & $2(0.2 \%)$ \\
\hline Meeting Abstract & $3(0.2 \%)$ \\
\hline News Item & $10(0.8 \%)$ \\
\hline Retraction & $1(0.1 \%)$ \\
\hline Review & $18(1.4 \%)$ \\
\hline \multicolumn{2}{|l|}{ Document Contents } \\
\hline Keywords Plus (ID) & 1422 \\
\hline Author's Keywords (DE) & 2711 \\
\hline \multicolumn{2}{|l|}{ Authors } \\
\hline Authors & 2830 \\
\hline Author Appearances & 4875 \\
\hline Authors of single-authored documents & 29 \\
\hline Authors of multi-authored documents & 2801 \\
\hline \multicolumn{2}{|l|}{ Authors Collaboration } \\
\hline Single-authored documents & 45 \\
\hline Documents per Author & 0.456 \\
\hline Authors per Document & 2.19 \\
\hline Co-Authors per Documents & 3.78 \\
\hline Collaboration Index & 2.25 \\
\hline
\end{tabular}




\section{Annual Production and Citation}

250

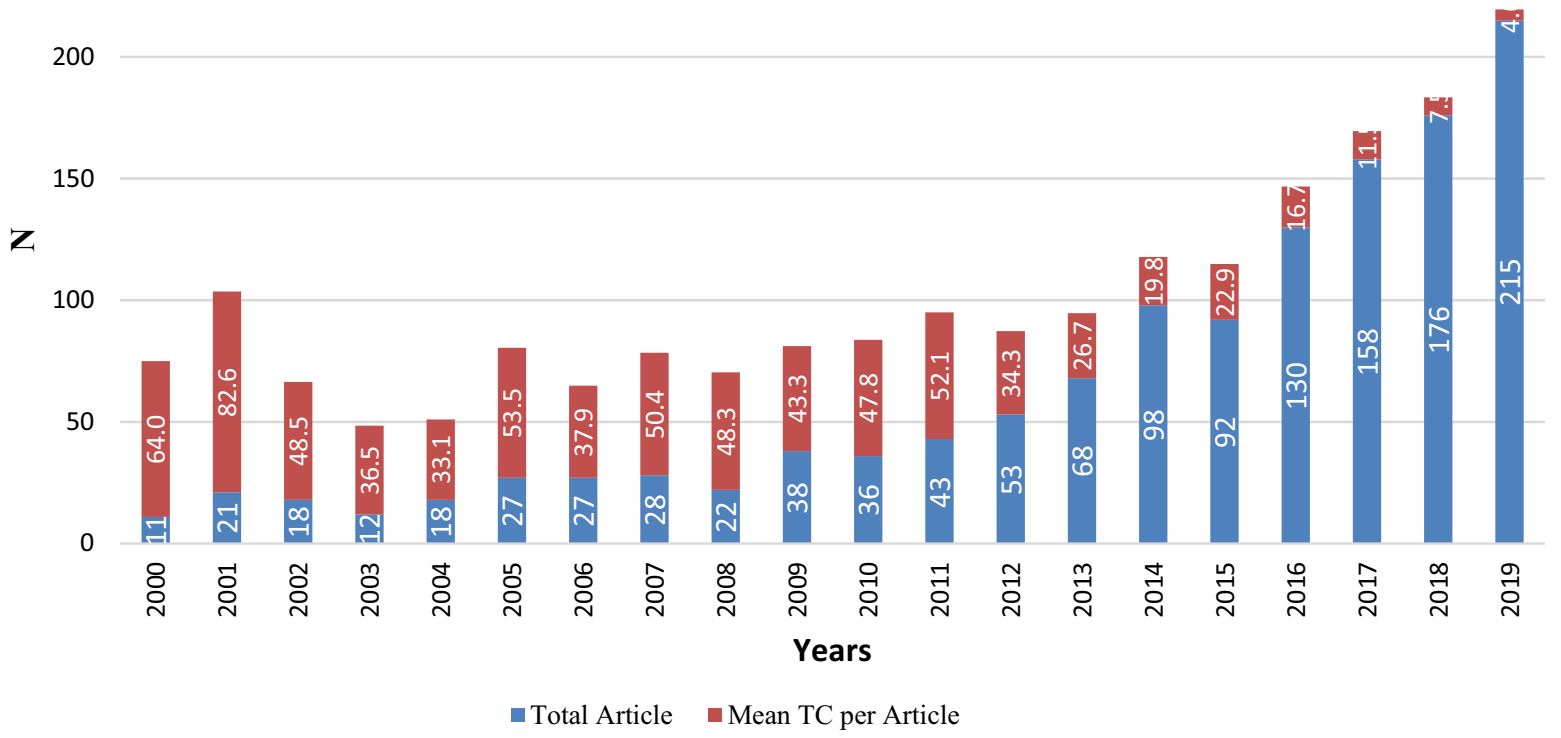

Fig. 1. Annual Production and Citation.

Table 3

Annual production and citation.

\begin{tabular}{lllll}
\hline Year & N & Mean TC per Article & Mean TC per Year & Citable Years \\
\hline 2000 & 11 & 64.00 & 3.20 & 20 \\
2001 & 21 & 82.57 & 4.35 & 19 \\
2002 & 18 & 48.50 & 2.69 & 18 \\
2003 & 12 & 36.50 & 2.15 & 17 \\
2004 & 18 & 33.11 & 2.07 & 16 \\
2005 & 27 & 53.52 & 3.57 & 15 \\
2006 & 27 & 37.85 & 2.70 & 13 \\
2007 & 28 & 50.43 & 3.88 & 12 \\
2008 & 22 & 48.32 & 4.03 & 11 \\
2009 & 38 & 43.26 & 3.93 & 10 \\
2010 & 36 & 47.81 & 4.78 & 9 \\
2011 & 43 & 52.14 & 5.79 & 8 \\
2012 & 53 & 34.28 & 4.29 & 7 \\
2013 & 68 & 26.66 & 3.81 & 6 \\
2014 & 98 & 19.80 & 3.30 & 5 \\
2015 & 92 & 22.86 & 4.57 & 4 \\
2016 & 130 & 16.71 & 4.18 & 3 \\
2017 & 158 & 11.54 & 3.85 & 2 \\
2018 & 176 & 7.51 & 3.76 & 1 \\
2019 & 215 & 4.62 & 4.62 & \\
\hline
\end{tabular}

of titanium alloy research. The top 20 list of most productive authors is shown in Table 4. Liu Z.Q with 29 number of publications (NP) has the highest number of documents published by him whereas Dargusch M.S is the highest contributor as well as an influential author with a total of $24 \mathrm{NP}$ and a total of 4270 total citation (TC). Both authors (Liu Z.Q and Dargusch M.S) have the same $h \_$index i.e 15 but publication start year (PY_start) are different i.e 2010 and 2007 respectively. Where 'R' stands for rank.

\subsection{Country wise publication analysis}

Authors from various institutions from different countries have published papers relating to machining of titanium alloy research. Table 5 shows the lists of top 20 most productive counties with TPTotal publication, TC- Total Citation, AAC- average article citation on machining of titanium alloy research. The most productive country is China with 678 TP and 6333 TC, followed by India with 346 TP and 3965 TC. Other productive countries publishing on machining of titanium alloy include developed countries as well as developing countries, suggesting that the research topic is receiving global attention. Again, the one new entrant in the analysis is Bangladesh ranked at number 20 in WoS with $1.16 \%$ of TP and 205 TC.

This analysis can be best visualized on the world map. Fig. 2 shows the global geographical distribution of machining of titanium alloy research outputs. This map is created by using Microsoft excel 2016 software. The map uses color-coding, where the dark orange world region has the largest number of publications, and the light pink world region has the least number of publications. Areas without color indicate that no publication is available in these areas. In this map, it can be seen that South Asian countries such as China, India are leading the research, followed by 
Table 4

Author production and impact.

\begin{tabular}{|c|c|c|c|c|c|c|c|}
\hline $\mathrm{R}$ & Author & h_index & g_index & m_index & TC & NP & PY_start \\
\hline 1 & Liu Z.Q & 15 & 25 & 1.364 & 636 & 29 & 2010 \\
\hline 2 & Dargusch M.S & 15 & 24 & 1.071 & 1109 & 24 & 2007 \\
\hline 3 & Sun J & 13 & 23 & 0.867 & 669 & 23 & 2006 \\
\hline 4 & Xu J.H & 11 & 17 & 0.647 & 326 & 23 & 2004 \\
\hline 5 & Fu Y.C & 10 & 16 & 0.588 & 283 & 20 & 2004 \\
\hline 6 & Li J.F & 12 & 18 & 1 & 365 & 18 & 2009 \\
\hline 7 & Chen M & 9 & 17 & 0.5 & 332 & 17 & 2003 \\
\hline 8 & An QL & 8 & 16 & 0.533 & 308 & 16 & 2006 \\
\hline 9 & Ding W.F & 9 & 15 & 0.9 & 251 & 16 & 2011 \\
\hline 10 & Singh $\mathrm{R}$ & 8 & 14 & 0.533 & 278 & 14 & 2006 \\
\hline 11 & Li L & 7 & 14 & 0.412 & 606 & 14 & 2004 \\
\hline 12 & He N & 6 & 13 & 0.4 & 537 & 13 & 2006 \\
\hline 13 & Palanisamy S & 10 & 13 & 0.714 & 513 & 13 & 2007 \\
\hline 14 & Wang B & 9 & 13 & 1.286 & 241 & 13 & 2014 \\
\hline 15 & Bruschi S & 8 & 12 & 1.333 & 235 & 12 & 2015 \\
\hline 16 & Mia M & 9 & 12 & 2.25 & 298 & 12 & 2017 \\
\hline 17 & Ozel T & 12 & 12 & 1.091 & 1358 & 12 & 2010 \\
\hline 18 & Balazinski M & 6 & 11 & 0.6 & 142 & 11 & 2011 \\
\hline 19 & Brandt M & 9 & 11 & 0.643 & 656 & 11 & 2007 \\
\hline 20 & Ghiotti A & 7 & 11 & 1.167 & 226 & 11 & 2015 \\
\hline
\end{tabular}

Table 5

Top 20 Countries publication.

\begin{tabular}{|c|c|c|c|c|c|c|}
\hline $\mathrm{R}$ & Countries & Frequency of TP & $\%$ & Country & TC & AAC \\
\hline 1 & China & 678 & 27.20 & China & 6333 & 15.75 \\
\hline 2 & India & 346 & 13.88 & USA & 5103 & 45.97 \\
\hline 3 & USA & 225 & 9.03 & India & 3965 & 21.20 \\
\hline 4 & Australia & 142 & 5.70 & Australia & 1971 & 31.79 \\
\hline 5 & UK & 119 & 4.77 & UK & 1531 & 26.40 \\
\hline 6 & France & 82 & 3.29 & France & 1393 & 38.69 \\
\hline 7 & Turkey & 81 & 3.25 & Malaysia & 1142 & 43.92 \\
\hline 8 & Japan & 63 & 2.53 & Turkey & 899 & 23.05 \\
\hline 9 & Germany & 59 & 2.37 & Italy & 868 & 27.12 \\
\hline 10 & Canada & 58 & 2.33 & Brazil & 665 & 23.75 \\
\hline 11 & Italy & 55 & 2.21 & Spain & 655 & 32.75 \\
\hline 12 & Poland & 53 & 2.13 & Germany & 628 & 21.66 \\
\hline 13 & Brazil & 52 & 2.09 & Japan & 412 & 16.48 \\
\hline 14 & Malaysia & 50 & 2.01 & Canada & 393 & 15.12 \\
\hline 15 & Spain & 42 & 1.68 & Singapore & 388 & 55.43 \\
\hline 16 & South Korea & 41 & 1.64 & Iran & 371 & 21.82 \\
\hline 17 & South Africa & 34 & 1.36 & Korea & 257 & 11.68 \\
\hline 18 & Sweden & 34 & 1.36 & Ireland & 220 & 110.00 \\
\hline 19 & Iran & 30 & 1.20 & South Africa & 218 & 12.82 \\
\hline 20 & Bangladesh & 29 & 1.16 & Bangladesh & 205 & 25.62 \\
\hline
\end{tabular}

North American countries like the USA, Canada. The Middle East countries and the African continent lag far behind other regions in this research field. Fig. 3 shows the country collaboration map on machining of titanium alloy research. In this figure, it is seen that China -USA has the strongest collaboration with 22 collaboration followed by China -the UK with 10 collaboration and India China with 7 collaboration receptively.

\subsection{Top institutions publishing work on machining of titanium alloy}

The list of top organizations publishing on machining of titanium alloy is shown in Table 6. Nanjing University of Aeronautics Astronautics is on the top with h-index of 10 with the highest number of publications (71 TP), followed by the Shandong University have the h-index of 9 with 55 TP. Indian Institute of Technology System (IIT System) India is in the third position with h-index of 8 and 54 TP. Northwestern Polytechnical University is on the last in the list of institutions with h-index of 2 . As can be seen from Table 6 , most of the publications from the institution of China.

\subsection{Top source impact analysis}

Most sources of high impact are also closely related to engineering disciplines. Table 7 lists the 20 most influential and most productive journals related to machining of titanium alloy. The progress and impact of research on reputable sources/journals are also reflected in Table 7. IJAMT is on the top of the list with $273 \mathrm{NP}$ getting 4615 TC followed by the journal of materials processing technology with 4038 TC from 70 NP. Interestingly, the journal of materials processing technology has the highest impact with 39 h_index on the research on machining of titanium alloy followed by IJAMT.

\subsection{Research discipline wise analysis}

In WoS database, most of the publications related to machining of titanium alloy research belong to the fields of engineering, materials science, business, automation control systems, metallurgy metallurgical engineering, and science technology. Table 8 lists 


\section{Distribution of Literature Publication}

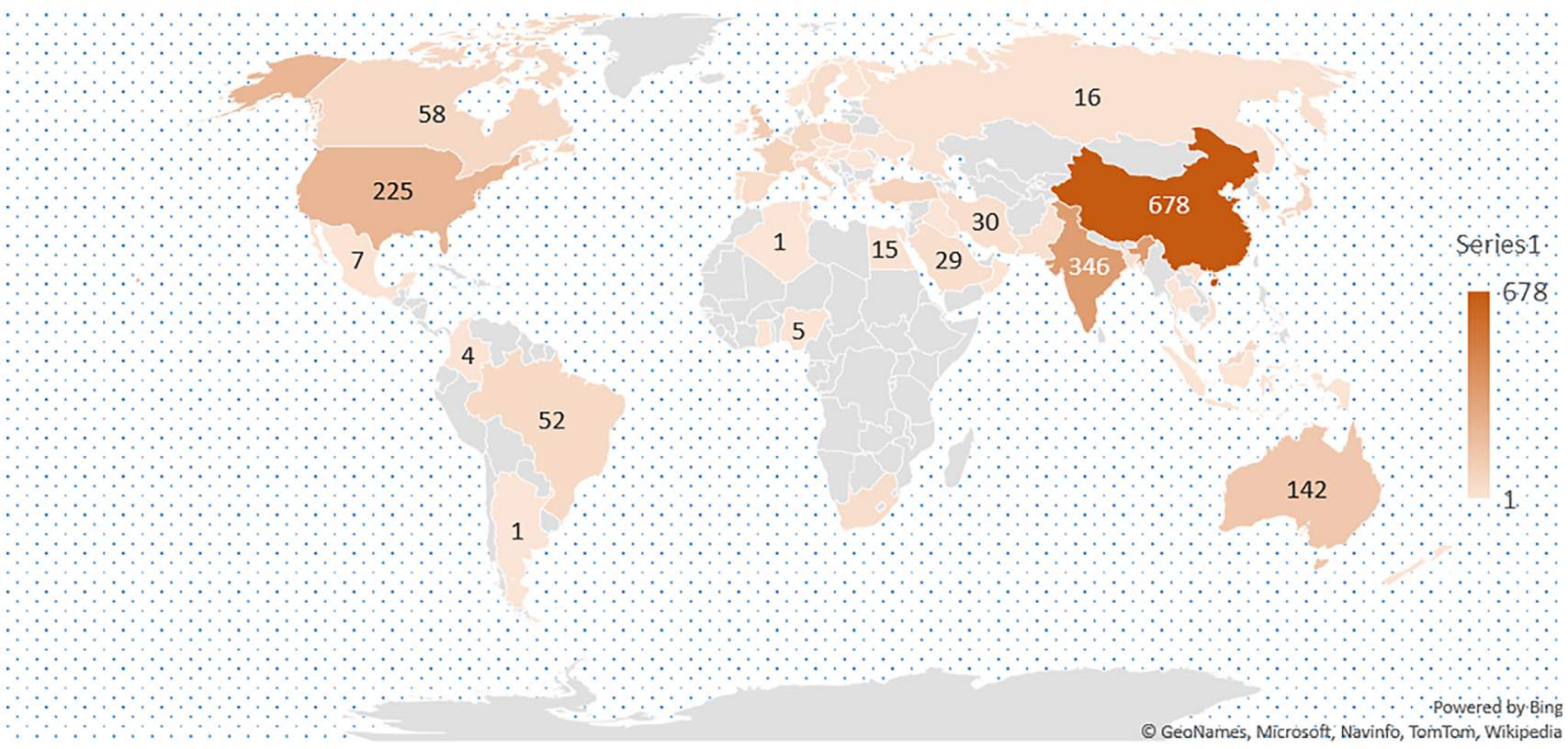

Fig. 2. Global Geographical Distribution of Machining of Titanium Alloy Research outputs.

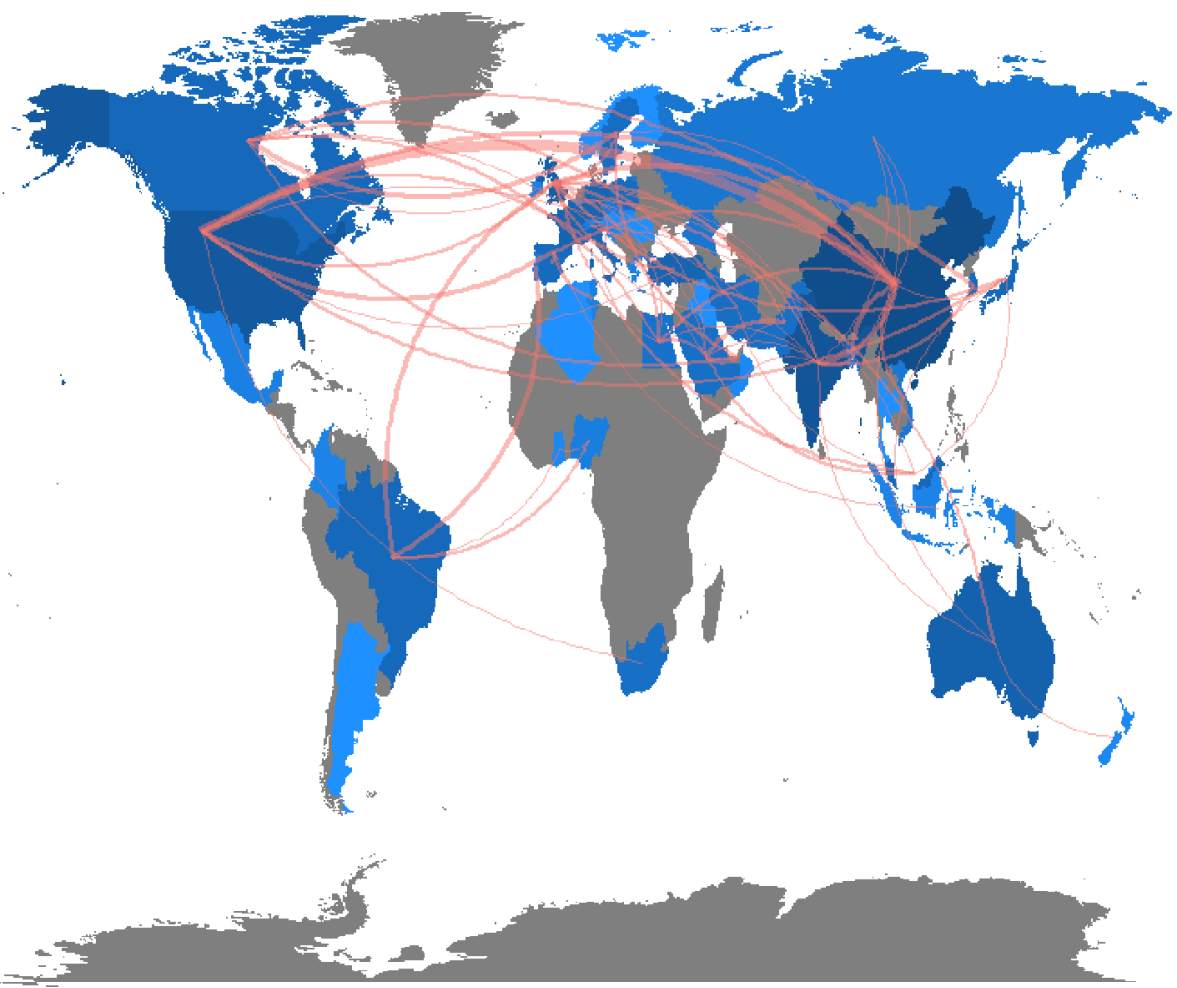

Fig. 3. Global Collaboration Map of Machining Research of Titanium Alloy.

the publications count in different research disciplines. It can be seen from Table 8 that there are 958 (73.46\%) and 470 (39.08\%) publications related to machining of titanium alloy in the engineering fields and materials science, respectively. Through this analysis, we can easily conclude that machining of titanium alloy is a comprehensive field of all disciplines.
3.7. Most frequent author keywords used in Machining of titanium alloy research

To understand the key areas of a topic in a specific field for a specific period, it is necessary to study the keywords of the research paper, because they can provide important details of the 
Table 6

Top Institutions publishing work on machining of titanium alloy.

\begin{tabular}{|c|c|c|c|}
\hline Institutions & Country & $\begin{array}{l}\text { TP } \\
\text { Record }\end{array}$ & $\%$ \\
\hline $\begin{array}{l}\text { Nanjing University of Aeronautics } \\
\text { Astronautics }\end{array}$ & China & 71 & 5.445 \\
\hline Shandong University & China & 55 & 4.218 \\
\hline $\begin{array}{l}\text { Indian Institute of Technology System (IIT } \\
\text { System) }\end{array}$ & India & 54 & 4.141 \\
\hline Shanghai Jiao Tong University & China & 37 & 2.837 \\
\hline University of Queensland & Australia & 28 & 2.147 \\
\hline Arts Et Metiers Institute of Technology & France & 26 & 1.994 \\
\hline Royal Melbourne Institute of Technology & Australia & 23 & 1.764 \\
\hline Anna University & India & 21 & 1.610 \\
\hline Swinburne University Of Technology & Australia & 19 & 1.457 \\
\hline Beihang University & China & 18 & 1.380 \\
\hline Georgia Institute Of Technology & USA & 18 & 1.380 \\
\hline Harbin Institute Of Technology & China & 18 & 1.380 \\
\hline University System Of Georgia & USA & 18 & 1.380 \\
\hline Indian Institute Of Technology IIT Bombay & India & 17 & 1.304 \\
\hline Northeastern University of China & China & 16 & 1.227 \\
\hline Northwestern Polytechnical University & China & 16 & 1.227 \\
\hline
\end{tabular}

current research field [34]. In WoS database, most of the extracted author keywords are linked to machining of titanium alloy. Table 9 shows the author keywords with keyword frequency. There are different types of keywords found from which the author keyword was considered for co-occurrence analysis. Where ' $F$ ' stands for the frequency of occurrence.

The author's keyword search can help to identify major research areas. For visual analysis, VoS Viewer was used to visualizing author keywords and co-occurrence networks. Different research topics are coloured in various colours so that corresponding keywords can be linked together. Certainly, over the past few years, keywords have changed dramatically. Fig. 4 shows the network visualization of author keywords in the field of machining of titanium alloy. From the analysis, it is clearly visible that different clusters are formed from the author keywords and each cluster showed a particular research theme. In cluster 1 the keywords are cutting fluid, minimum quantity lubrication (MQL), lubrication, Nanofluid, cutting forces, cryogenic machining, temperature, cutting parameters and surface morphology, etc. In cluster 2 the keywords are roughness, optimization, EDM, Taguchi method, FEM, MRR, residual stress, and Numerical Simulation, etc. In cluster 3 the keywords are Flank Wear, crater wear, wear mechanism, PCD
Table 8

Top research discipline on machining of titanium alloy.

\begin{tabular}{lll}
\hline Research discipline & Record Count & $\%$ \\
\hline Engineering & 958 & 73.466 \\
Materials Science & 470 & 36.043 \\
Automation Control Systems & 275 & 21.089 \\
Metallurgy Metallurgical Engineering & 124 & 9.509 \\
Science Technology Other Topics & 78 & 5.982 \\
Physics & 44 & 3.374 \\
Chemistry & 41 & 3.144 \\
Instruments Instrumentation & 36 & 2.761 \\
Mechanics & 33 & 2.531 \\
Computer Science & 16 & 1.227 \\
Electrochemistry & 14 & 1.074 \\
Environmental Sciences Ecology & 14 & 1.074 \\
Thermodynamics & 14 & 1.074 \\
Dentistry Oral Surgery Medicine & 12 & 0.920 \\
Energy Fuels & 8 & 0.613 \\
Optics & 7 & 0.537 \\
Operations Research Management Science & 6 & 0.460 \\
Mathematics & 5 & 0.383 \\
Acoustics & 4 & 0.307 \\
Orthopedics & 4 & 0.307 \\
\hline
\end{tabular}

tool, tool life, and cutting tool. In cluster 4 the keyword is chip formation, chip mechanism, chip formation, microstructure, and serrated chip formation. In cluster 5 the keywords are drilling, hole quality, composite, and optimization.

\section{Implications and limitations of the research}

This study appends the literature on machining of titanium alloy. The bibliometric analysis will be used to provide a general outline and overall structure of the research area. For practitioners, this study provides important implications such as where is machining of titanium alloy research is going? The insight gained from this analysis also has implications for industrial peoples and academic scholars. From the industrial person point of view, the findings of this study help in the decision making process for the selection of research in the field of machining of titanium alloy. On the other hand, in the academic scholar point of view, this study gives a direction for starting new future research work in this field.

This research has some limitations. In this study only WoS database is used for bibliometric analysis. Although this database is very comprehensive and valid, it is better to use other databases,

Table 7

Top journals publishing works on machining of titanium alloy research.

\begin{tabular}{|c|c|c|c|c|c|c|}
\hline Source & h_index & g_index & m_index & $\mathrm{TC}$ & NP & PY_start \\
\hline IJAMT & 35 & 50 & 2.33 & 4615 & 273 & 2006 \\
\hline Journal of Materials Processing Technology & 39 & 63 & 1.86 & 4038 & 70 & 2000 \\
\hline Proceedings of The Institution of Mechanical Engineers Part B-Journal of Engineering Manufacture & 17 & 24 & 0.89 & 826 & 62 & 2002 \\
\hline Materials and Manufacturing Processes & 20 & 30 & 1.54 & 1028 & 48 & 2008 \\
\hline International Journal of Machine Tools \& Manufacture & 30 & 41 & 1.50 & 4098 & 41 & 2001 \\
\hline Journal of Manufacturing Processes & 13 & 19 & 1.63 & 480 & 35 & 2013 \\
\hline Machining Science and Technology & 15 & 25 & 0.83 & 666 & 34 & 2003 \\
\hline Journal of Manufacturing Science and Engineering-Transactions of The ASME & 12 & 17 & 0.75 & 346 & 32 & 2005 \\
\hline 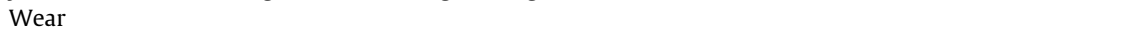 & 17 & 29 & 0.85 & 1253 & 29 & 2001 \\
\hline Materials & 8 & 10 & 1.00 & 146 & 22 & 2013 \\
\hline CIRP Annals-Manufacturing Technology & 13 & 17 & 0.68 & 867 & 17 & 2002 \\
\hline Journal of Alloys and Compounds & 11 & 17 & 0.52 & 555 & 17 & 2000 \\
\hline Journal of The Brazilian Society of Mechanical Sciences and Engineering & 8 & 12 & 0.62 & 153 & 16 & 2008 \\
\hline Materials Science and Engineering A-Structural Materials Properties Microstructure and Processing & 12 & 14 & 0.63 & 457 & 14 & 2002 \\
\hline Tribology International & 11 & 14 & 0.92 & 475 & 14 & 2009 \\
\hline Journal of Cleaner Production & 9 & 13 & 1.29 & 277 & 13 & 2014 \\
\hline Precision Engineering-Journal of The International Societies for Precision Engineering and Nanotechnology & 10 & 13 & 0.50 & 367 & 13 & 2001 \\
\hline International Journal of Precision Engineering and Manufacturing & 7 & 12 & 0.78 & 259 & 12 & 2012 \\
\hline Measurement & 10 & 12 & 1.11 & 416 & 12 & 2012 \\
\hline Metals & 5 & 9 & 0.71 & 89 & 12 & 2014 \\
\hline
\end{tabular}


Table 9

Top 100 Author Keywords on machining of titanium alloy research.

\begin{tabular}{|c|c|c|c|c|c|}
\hline Keywords & $\mathrm{F}$ & Keywords & $\mathrm{F}$ & Keywords & $\mathrm{F}$ \\
\hline Titanium Alloy (Ti-6al-4v) & 890 & Taguchi Method & 17 & Crater Wear & 8 \\
\hline Tool Wear & 151 & Cryogenic & 17 & Delamination & 8 \\
\hline Machining & 127 & Modeling & 16 & Flank Wear & 8 \\
\hline Surface Roughness & 101 & End Milling & 15 & Numerical Simulation & 8 \\
\hline Milling & 71 & High-Speed Machining & 14 & Recast Layer & 8 \\
\hline Drilling & 69 & Lubrication & 14 & Surface Modification & 8 \\
\hline Cutting Force & 59 & Microhardness & 14 & Surface Morphology & 8 \\
\hline Surface Integrity & 57 & MRR & 14 & Sustainable Machining & 8 \\
\hline Surface & 50 & Taguchi & 14 & Torque & 8 \\
\hline Turning & 50 & Dry Machining & 14 & Analysis of Variance & 7 \\
\hline Wear & 41 & Surface Topography & 13 & Artificial Neural Network & 7 \\
\hline Tool Life & 39 & Ultrasonic Machining & 13 & Chatter & 7 \\
\hline Roughness & 38 & Wear Mechanism & 13 & Cutting Speed & 7 \\
\hline Optimization & 35 & Forces & 13 & Electric Discharge Machining & 7 \\
\hline Cutting & 34 & High-Speed Machining & 12 & Finite Element Analysis & 7 \\
\hline Cutting Forces & 32 & Hole Quality & 12 & Laser-Assisted Machining & 7 \\
\hline Machinability & 32 & Surface Finish & 12 & Laser Drilling & 7 \\
\hline Microstructure & 32 & X-Ray Diffraction & 12 & Mechanical Milling & 7 \\
\hline Temperature & 32 & Cryogenic Cooling & 12 & Mechanical Properties & 7 \\
\hline Chip Morphology & 29 & Micro-EDM & 11 & Micro-End Milling & 7 \\
\hline EDM & 28 & Residual Stresses & 11 & Tool Wear Rate & 7 \\
\hline Grinding & 28 & Thrust Force & 11 & Ultrasonic Vibration & 7 \\
\hline Material Removal Rate & 27 & Burr Formation & 11 & WEDM & 7 \\
\hline Residual Stress & 26 & Machining Performance & 10 & Adhesion & 6 \\
\hline Cutting Temperature & 24 & Micro-Milling & 10 & Carbide & 6 \\
\hline Cryogenic Machining & 22 & Morphology & 10 & Chip Segmentation & 6 \\
\hline Finite Element Method & 22 & Simulation & 10 & Cryogenic Treatment & 6 \\
\hline Chip Formation & 21 & Surface Quality & 10 & Cutting Tool & 6 \\
\hline MQL & 21 & ANOVA & 9 & Electrode & 6 \\
\hline High-Speed Milling & 20 & Diffusion & 9 & Energy Efficiency & 6 \\
\hline Chip & 19 & Electrochemical Machining & 9 & FE Simulation & 6 \\
\hline Force & 18 & Friction & 9 & Grinding Force & 6 \\
\hline Minimum Quantity Lubrication & 18 & RSM & 9 & Grinding Forces & 6 \\
\hline Tool & 18 & Vibration & 9 & High Speed & 6 \\
\hline Electrical Discharge Machining & 18 & Coating & 8 & High-Speed Milling & 6 \\
\hline FEM & 17 & Cooling & 8 & Nanofluids & 6 \\
\hline
\end{tabular}

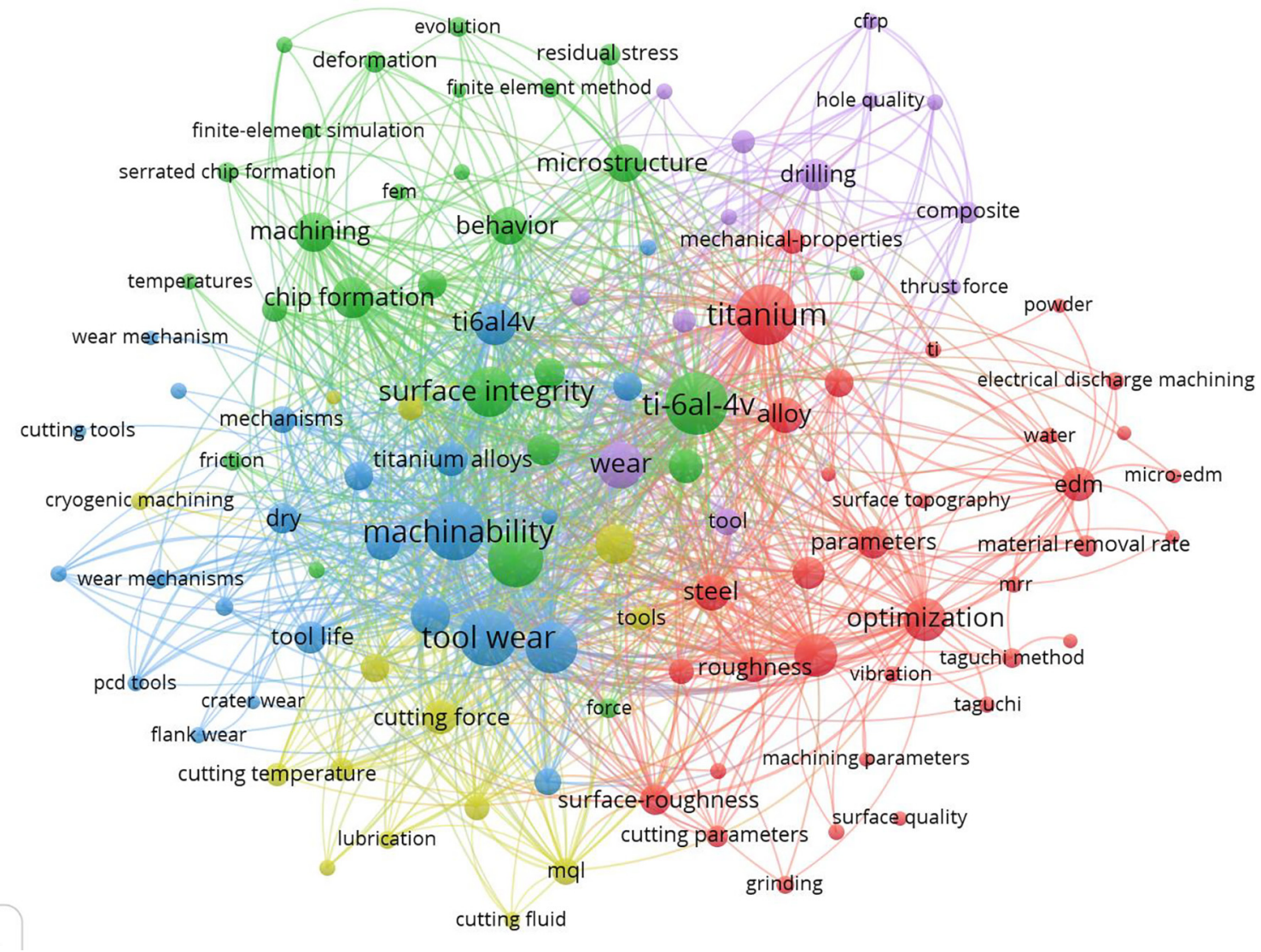

Fig. 4. Author Keywords co-occurrence analysis. 
including the Scopus database and Google Scholar. Another limitation is that our research includes publications in the English language only, and it is recommended that future research include documents published in other languages.

\section{Conclusion}

This article presents a bibliometric analysis of machining of titanium alloy research publications from 1st January 2000 to 31st December 2019 from the WoS database. An overview of the research on machining of titanium alloy was presented with the information related to the number of documents published on machining of titanium alloy, their language-wise distribution, type of documents, chronological publications count, top authors, journals, universities, and countries publishing documents. Based on the descriptive finding, the annual growth rate in machining of titanium alloy research is $16.94 \%$, which indicates that machining of titanium alloy research has gained rapid attention since 2016 and gradually evolved over the years. Moreover, most of the research on machining of titanium alloy has been done in the engineering and material science field. From a quantitative perspective, China and India are leading countries but on the other hand in the view of a qualitative perspective, China and the USA are on the top. Consequently, the visualization diagram of keywords created by VoS viewer using WoS data files shows that the field of machining of titanium alloy has a great scope in the future in the directions like minimum quantity lubrication (MQL), nanofluid, cryogenic machining, cutting temperature, CFD, microstructure, sustainable machining, green machining, tool wear, nano machining, optimization, tool life with major machining process like turning, milling, grinding, drilling, EDM and WEDM, etc. From the Journal wise analysis, IJAMT (4615(TC), 273(NP)), and JMPT (h index 39) have a good quality of published publications. It is seen that Liu Z.Q who holds the first position with 29 publications and $15 \mathrm{~h}$-index. Similar is the case with other authors as well. Although China dominates in the machining of titanium alloy research around the world but Nanjing University of Aeronautics Astronautics, china has maximum research outputs than other universities around the world. Country collaborating wise, China-USA is leading in the world as their combined research output is the highest.

\section{CRediT authorship contribution statement}

Gaurav Gaurav: Conceptualization, Writing - original draft, W, riting - review \& editing. Abhay Sharma: Investigation, Methodology. G.S. Dangayach: Supervision. M.L. Meena: Supervision.

\section{Declaration of Competing Interest}

The authors declare that they have no known competing financial interests or personal relationships that could have appeared to influence the work reported in this paper.

\section{References}

[1] A. Hasçalık, U. Çaydaș, Electrical discharge machining of titanium alloy (Ti6Al-4V), Appl. Surf. Sci. 253 (22) (2007) 9007-9016.

[2] P. Singh, H. Pungotra, N.S. Kalsi, On the complexities in machining titanium alloys, in: InCAD/CAM, Robotics and Factories of the Future 2016, Springer, New Delhi, 2016, pp. 499-507.

[3] R.S. Revuru, N.R. Posinasetti, V.R. VSN, M. Amrita, Application of cutting fluids in machining of titanium alloys-a review, Int. J. Adv. Manufact. Technol. 91 (58) (2017) 2477-2498.

[4] E.O. Ezugwu, J. Bonney, Y. Yamane, An overview of the machinability of aeroengine alloys, J. Mater. Process. Technol. 134 (2) (2003) 233-253.
[5] E.O. Ezugwu, Z.M. Wang, Titanium alloys and their machinability-a review, J. Mater. Process. Technol. 68 (3) (1997) 262-274.

[6] Y. Su, L. Gong, B. Li, Z. Liu, D. Chen, Performance evaluation of nanofluid MQL with vegetable-based oil and ester oil as base fluids in turning, Int. J. Adv. Manuf. Technol. 83 (9-12) (2016) 2083-2089.

[7] K.A. Venugopal, S. Paul, A.B. Chattopadhyay, Growth of tool wear in turning of Ti-6Al-4V alloy under cryogenic cooling, Wear 262 (9-10) (2007) 1071-1078.

[8] N. Banerjee, A. Sharma, Multi-point injection minimum quantity lubrication machining, in: In Materials Science Forum, Trans Tech Publications Ltd., 2015, pp. $108-111$.

[9] J. Sun, Y.B. Guo, A comprehensive experimental study on surface integrity by end milling Ti-6Al-4V, J. Mater. Process. Technol. 209 (8) (2009) 4036-4042.

[10] C. Ohkubo, I. Watanabe, J.P. Ford, H. Nakajima, T. Hosoi, T. Okabe, The machinability of cast titanium and Ti-6Al-4V, Biomater. 21 (4) (2000) 421428.

[11] P.J. Arrazola, A. Garay, L.M. Iriarte, M. Armendia, S. Marya, F. Le Maître, Machinability of titanium alloys (Ti6Al4V and Ti555. 3), J. Mater. Process. Technol. 209 (5) (2009) 2223-2230.

[12] M. Kikuchi, The use of cutting temperature to evaluate the machinability of titanium alloys, Acta Biomater. 5 (2) (2009) 770-775.

[13] W.Q. Song, S. Sun, S. Zhu, G. Wang, J. Wang, M.S. Dargusch, Compressive deformation behavior of a near-beta titanium alloy, Mater. Des. 1 (34) (2012) 739-745.

[14] C.R. Dandekar, Y.C. Shin, J. Barnes, Machinability improvement of titanium alloy (Ti-6Al-4V) via LAM and hybrid machining, Int. J. Mach. Tools Manuf 50 (2) (2010) 174-182.

[15] N. Khanna, K.S. Sangwan, Comparative machinability study on Ti54M titanium alloy in different heat treatment conditions, Proceed. Institut. Mech. Eng. Part B J. Eng. Manuf. 227 (1) (2013) 96-101.

[16] J.H. Yang, M. Brandt, S.J. Sun, Numerical and experimental investigation of the heat-affected zone in a laser-assisted machining of Ti-6Al-4V alloy process, Trans Tech Publications Ltd. 618 (2009) 143-146.

[17] S.Y. Hong, Y. Ding, Cooling approaches and cutting temperatures in cryogenic machining of Ti-6Al-4V, Int. J. Mach. Tools Manuf 41 (10) (2001) 1417-1437.

[18] S.Y. Hong, I. Markus, W.C. Jeong, New cooling approach and tool life improvement in cryogenic machining of titanium alloy Ti-6Al-4V, Int. J. Mach. Tools Manuf 41 (15) (2001) 2245-2260.

[19] S. Palanisamy, S.D. McDonald, M.S. Dargusch, Effects of coolant pressure on chip formation while turning Ti6Al4V alloy, Int. J. Mach. Tools Manuf 49 (9) (2009) 739-743.

[20] Q.L. An, Y.C. Fu, J.H. Xu, Experimental study on turning of TC9 titanium alloy with cold water mist jet cooling, Int. J. Mach. Tools Manuf. 51 (6) (2011) 549555.

[21] E.A. Rahim, S. Sharif, Investigation on tool life and surface integrity when drilling Ti-6Al-4V and Ti-5Al-4V-Mo/Fe, JSME Int J. Ser. C. Mech. Syst. Mach. Elem. Manuf. 49 (2) (2006) 340-345.

[22] T. Thepsonthi, T. Özel, Experimental and finite element simulation based investigations on micro-milling Ti-6Al-4V titanium alloy: Effects of cBN coating on tool wear, J. Mater. Process. Technol. 213 (4) (2013) 532-542.

[23] N. Banerjee, A. Sharma, Identification of a friction model for minimum quantity lubrication machining, J. Cleaner Produc. 15 (83) (2014) 437-443.

[24] N. Banerjee, A. Sharma, Development of a friction model and its application in finite element analysis of minimum quantity lubrication machining of Ti-6Al-4 V, J. Mater. Process. Technol. 1 (238) (2016 Dec) 181-194.

[25] N. Banerjee, A. Sharma, A comprehensive assessment of minimum quantity lubrication machining from quality, production, and sustainability perspectives, Sustain. Mater. Technol. 1 (17) (2018) e00070.

[26] N. Banerjee, A. Sharma, Improving machining performance of Ti-6Al-4V through multi-point minimum quantity lubrication method, Proceed. Instit. Mech. Eng. Part B J. Eng. Manuf. 233 (1) (2019) 321-336.

[27] G. Gaurav, A. Sharma, G.S. Dangayach, M.L. Meena, Assessment of jojoba as a pure and nano-fluid base oil in minimum quantity lubrication (MQL) hardturning of Ti-6Al-4V: A step towards sustainable machining, J. Cleaner Prod. 1 (272) (2020) 122553.

[28] N. Talib, H. Sasahara, E.A. Rahim, Evaluation of modified jatropha-based oil with hexagonal boron nitride particle as a biolubricant in orthogonal cutting process, Int. J. Adv. Manuf. Technol. 92 (1-4) (2017) 371-391.

[29] A.K. Sharma, A.K. Tiwari, A.R. Dixit, Effects of Minimum Quantity Lubrication (MQL) in machining processes using conventional and nanofluid based cutting fluids: A comprehensive review, J. Cleaner Prod. 20 (127) (2016) 1-8.

[30] A. Pritchard, Statistical bibliography or bibliometrics, J. Document. 25 (4) (1969) 348-349.

[31] O. Persson, W. Glänzel, R. Danell, Inflationary bibliometric values: The role of scientific collaboration and the need for relative indicators in evaluative studies, Scientometr. 60 (3) (2004) 421-432.

[32] N.J. Van Eck, L. Waltman, Software survey: VOSviewer, a computer program for bibliometric mapping, Scientometr. 84 (2) (2010) 523-538.

[33] M. Aria, C. Cuccurullo, bibliometrix: An R-tool for comprehensive science mapping analysis, J. Informetr. 11 (4) (2017) 959-975.

[34] Y. Wei, P.J. McGrath, J. Hayden, S. Kutcher, Mental health literacy measures evaluating knowledge, attitudes and help-seeking: a scoping review, BMC Psychiatry. 15 (1) (2015) 291. 